Short communication

\title{
Comparative investigations on the biological effects of As (III) and As (V) in clam Ruditapes philippinarum using multiple biomarkers
}

\author{
Chenglong Ji ${ }^{\text {a, } 1}$, Hai'e Xu ${ }^{\text {b, }}{ }^{\text {, }}$ Qing Wang ${ }^{\text {, }}$ Jianmin Zhao a , Huifeng Wu ${ }^{\text {a, * }}$ \\ a Key Laboratory of Coastal Zone Environmental Processes, Yantai Institute of Coastal Zone Research (YIC), Chinese Academy of Sciences (CAS); Shandong \\ Provincial Key Laboratory of Coastal Zone Environmental Processes, YICCAS, Yantai 264003, PR China \\ b Clinical Nutrition, The Second Affiliated Hospital of Nanjing Medical University, Nanjing 210011. China
}

\section{A R T I C L E I N F O}

Article history:

Received 29 June 2015

Received in revised form 26 August 2015

Accepted 26 August 2015

Available online 29 August 2015

\section{Keywords:}

Ruditapes philippinarum

Arsenic

Biological effects

Metabolomics

\begin{abstract}
A B S T R A C T
Inorganic arsenic is a known pollutant with two chemical forms, arsenite (As (III)) and arsenate (As (V)), in marine environment. Clam Ruditapes philippinarum is an important fishery species along the Bohai coast. In this study, the biological effects induced by the two arsenic chemical forms (arsenite and arsenate) were compared using multiple biochemical indices in the digestive glands of clam R. philippinarum. The production of reactive oxygen species, antioxidant enzyme activities and metabolic responses exhibited that both As (III) and As (V) induced immune, oxidative and osmotic stresses in clam digestive glands. The differential metabolic biomarkers, histidine and taurine, indicated the differential responsive mechanisms in osmotic regulation in clam digestive glands. In addition, both arsenic treatments enhanced the anaerobiosis metabolism in clam digestive glands. Overall, this work illustrated that arsenite and arsenate induced similar biological effects in clams, which might be accounted for the biological transformation of arsenate to arsenite in clams.
\end{abstract}

() 2015 Elsevier Ltd. All rights reserved.

\section{Introduction}

Arsenic (As) is a known metalloid pollutant that is toxic to marine organisms [1]. Due to the development of industry, arsenic was discharged to estuarine and coastal environments with an average amount more than 5000 tons/year in China from 2007 to 2010 [2]. In aquatic environment, arsenic may occur in different chemical forms, including inorganic forms of arsenite (As (III)) and arsenate (As (V)) and organic forms such as arsenoribosides, arsenobetaine, monomethylarsonic acid and dimethylarsinic acid [3]. In open ocean seawater, the concentration of total arsenic is usually around $1-3 \mu \mathrm{g} / \mathrm{L}[4]$.

The toxicity of arsenic varies widely with its chemical forms and the inorganic arsenic species, As (III) and arsenate As (V), are considerably more toxic than the organic arsenic species [5]. In addition, As (III) is about 60 times more toxic than As (V) to human body. The concentration of As (V) is usually higher than that of As (III) in seawater, however, the concentration of As (III) is still approximately $13 \%$ of the concentration of arsenate in the seawater

\footnotetext{
* Corresponding author.

E-mail address: hfwu@yic.ac.cn (H. Wu).

1 These two authors contributed equally to this work.
}

along the coast [4]. Due to the higher toxicity of As (III) than As (V), the biological effects of As (III) should not be ignored. However, the differentiation of the toxicities between As (III) and As (V) was not fully characterized in marine organisms, such as marine bivalves. Therefore, it is necessary to compare the biological effects between the two inorganic chemical forms, As (III) and As (V), in marine organisms.

With the development of -omic techniques, including genomics, transcriptomics, proteomics and metabolomics, a global profiling of the biological responses may be used to elucidate the biological perturbations in organisms exposed by environmental stressors [6-9]. As a newly established -omic technique, metabolomics focuses on all the low molecular weight $(<1000 \mathrm{Da})$ metabolites in biological samples [10,11], and may present an insightful view into the pollutant-induced effects in marine organisms [12-16].

Manila clam Ruditapes philippinarum is one of the most important economic species in marine aquaculture in China. And it is frequently used as a preferable bioindicator in pollution biomonitoring [17-19]. In this study, the biochemical responses induced by As (III) and As were compared by using multiple biochemical indices, including metabolic profiling, the total haemocyte count (THC), production of reactive oxygen species and antioxidant enzyme activities in clam $R$. philippinarum after acute 
exposure for $48 \mathrm{~h}$. This study may present the differentiation between the biological effects induced by As (III) and As (V) in clams and better understand the inorganic arsenic-induced effects.

\section{Materials and methods}

\subsection{Experimental animals and conditions}

Twenty four adult clams $R$. philippinarum (shell length: $3.5-3.8 \mathrm{~cm}, n=8$ from White pedigree) were purchased from a local culturing farm in Yantai, China. After transported to the laboratory, the animals were allowed to acclimate in aerated seawater $\left(25^{\circ} \mathrm{C}, 33 \mathrm{psu}\right.$, collected from pristine environment) for 1 week and fed with the Chlorella vulgaris Beij at a ration of $2 \%$ tissue dry weight daily. After acclimation, the clams were randomly divided into three tanks (control, arsenite $\left(\mathrm{NaAsO}_{2}, \mathrm{As}\right.$ (III)) and arsenate $\left(\mathrm{NaHAsO}_{4}\right.$, As (V)) exposures) containing eight individual clams in $20 \mathrm{~L}$ aerated seawater. The experimental concentration of As (V) was set at $20 \mu \mathrm{g} / \mathrm{L}$ that was environmental relevant $[4,20]$. The environmental concentration of As (III) is usually around $10 \%$ of that As (V). In this study, however, the same concentration $(20 \mu \mathrm{g} / \mathrm{L})$ of As (III) was used to compare the biological effects induced by these two inorganic forms of As in clam R. philippinarum. After exposure for $48 \mathrm{~h}$, the hemolymph (approx. $350 \mu \mathrm{L}$ per sample) was sampled from the adductor muscle by a sterile syringe with the same volume of anticoagulant (50.0 mM Tris, $111.0 \mathrm{mM}$ Glucose, $341.9 \mathrm{mM}$ $\mathrm{NaCl}, 25.5 \mathrm{mM}$ EDTA, pH 7.4). Samples were immediately filtered through a nylon mesh and kept individually in tubes held on ice to prevent hemocyte clumping until use. Then the digestive gland tissues of all the clams were dissected quickly and divided into three parts for metabolite extraction, assessment of antioxidant enzyme activities and determination of total arsenic in clam samples. These samples were flash-frozen in liquid nitrogen and stored at $-80^{\circ} \mathrm{C}$ before further procedures.

\subsection{Total haemocyte count and reactive oxygen species}

The counting of free hemocytes was done by using a Neubauer hemocytometer according to a previous study with some minor modifications [21]. The hemocyte suspension fixed with 4\% formalin was vortexed before transferring an aliquot of the suspension to a hemocytometer to quantify the total hemocytes under a light microscope (Olympus BX61, Tokyo, Japan). Three separate aliquots of the hemocyte suspension were counted and averaged for each clam. The data were presented as number of hemocytes/ mL hemolymph.

The production of reactive oxygen species (ROS) in hemolymph was assayed using $2^{\prime}, 7^{\prime}$-dichlorofluorescein diacetate (DCFH-DA, Sigma). Inside hemocytes, the -DA radicals is firstly hydrolyzed by esterase enzymes, and converted to $2^{\prime}, 7^{\prime}$-diclorofluorescein (DCFH), which emits fluorescence when reacting with ROS produced by the cell. Hemocyte suspensions diluted with PBS (341.9 mM NaCl,

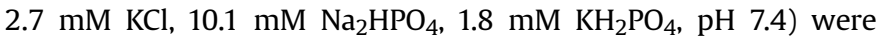
allowed to adhere for $20 \mathrm{~min}$ before adding DCFH-DA with the final concentration of $10 \mu \mathrm{M}$. After $60 \mathrm{~min}$ incubation at $18{ }^{\circ} \mathrm{C}, \mathrm{DCF}$ fluorescence intensity was measured using a flow cytometer (Becton-Dickinson, San Diego, CA, USA). The mean of fluorescence intensity of hemocyte population was expressed as arbitrary unit $(\mathrm{AU})$.

\subsection{Metabolite extraction}

Polar metabolites in clam tissues ( $n=8$ for each treatment) were extracted by the modified extraction protocol as described previously [15]. Briefly, the digestive gland tissue $(\sim 100 \mathrm{mg}$ wet weight) was homogenized and extracted in $4 \mathrm{~mL} / \mathrm{g}$ of methanol, $5.25 \mathrm{~mL} / \mathrm{g}$ of water and $2 \mathrm{~mL} / \mathrm{g}$ of chloroform. The methanol/water layer with polar metabolites was transferred to a glass vial and dried in a centrifugal concentrator. The extracts were then resuspended in $600 \mu \mathrm{L}$ of phosphate buffer $\left(100 \mathrm{mM} \mathrm{Na}_{2} \mathrm{HPO}_{4}\right.$ and $\mathrm{NaH}_{2} \mathrm{PO}_{4}$, including $0.5 \mathrm{mM}$ TSP, $\mathrm{pH} 7.0$ ) in $\mathrm{D}_{2} \mathrm{O}$. The mixture wAs (V)ortexed and then centrifuged at $3000 \mathrm{~g}$ for $5 \mathrm{~min}$ at $4{ }^{\circ} \mathrm{C}$. The supernatant substance $(550 \mu \mathrm{L})$ was then pipetted into a $5 \mathrm{~mm}$ NMR tube prior to NMR analysis.

\section{4. ${ }^{1}$ H NMR spectroscopy}

Metabolite extracts of digestive gland tissues from clams were analyzed on a Bruker AV 500 NMR spectrometer performed at $500.18 \mathrm{MHz}$ (at $25{ }^{\circ} \mathrm{C}$ ) as described previously [15]. All ${ }^{1} \mathrm{H}$ NMR spectra were phased, baseline-corrected, and calibrated (TSP at $0.0 \mathrm{ppm}$ ) manually using TopSpin (version 2.1, Bruker).

\subsection{Spectral pre-processing and multivariate analysis}

All one dimensional ${ }^{1} \mathrm{H}$ NMR spectra were converted to a data matrix using the custom-written ProMetab software in Matlab version 7.0 (The MathsWorks, Natick, MA) [15]. Each spectrum was segmented into bins with a width of $0.005 \mathrm{ppm}$ between 0.2 and $10.0 \mathrm{ppm}$. The bins of residual water peak between 4.70 and $5.20 \mathrm{ppm}$ were excluded from all the NMR spectra. The total spectral area of the remaining bins was normalized to unity to facilitate the comparison between the spectra. All the NMR spectra were generalized log transformed (glog) with a transformation parameter $\lambda=1.0 \times 10^{-8}$ to stabilize the variance across the spectral bins and to increase the weightings of the less intense peaks [15]. As described in details in our previous work, data were mean-centered before multivariate data analysis. The supervised pattern recognition method, partial least squares discriminant analysis (PLS-DA) and orthogonal projection to latent structure with discriminant analysis (O-PLS-DA), were sequentially carried out to uncover and extract the statistically significant metabolite variations related to inorganic As exposures, as described previously [22]. Metabolites were assigned following the tabulated chemical shifts and by using the software, Chenomx (Evaluation Version, Chenomx Inc., Edmonton, Alberta, Canada) [23].

\subsection{Antioxidant enzyme activities}

The antioxidant enzyme activities in the digestive gland tissues ( $n=8$ ) of $R$. philippinarum were assayed using a multimode microplate reader (Infinite M200, TECAN, Switzerland) according to the manufacturer's protocols for enzyme kits (Jiancheng, Nanjing, China). In this work, the antioxidant enzymes for the activity measurement included superoxide dismutase (SOD, EC 1.15.1.1), glutathione S-transferase (GST, EC 2.5.1.18) and glutathione peroxidase (GPX, EC 1.11.1.9). Protein concentration was determined by the Coomassie brilliant blue G-250 dye-binding method with bovine serum albumin as standard [24]. The unit of each enzyme was defined as the activity of an enzyme per milligram of total protein (U/mg protein).

\subsection{Determination of total arsenic in clam digestive gland tissues}

Six digestive gland samples in each group were dried at $80^{\circ} \mathrm{C}$ to constant weights, and then digested in $1 \mathrm{~mL}$ of concentrated nitric acid (70\%, Fisher Scientific) using a microwave digestion system (CEM, MAR5). All completely digested samples were diluted with ultrapure water to $5 \mathrm{~mL}$ for the determination of arsenic. Total arsenic concentrations were analyzed using an inductively coupled 
Table 1

Biochemical indices in clam R. philippinarum samples after As exposures for $48 \mathrm{~h}$.

\begin{tabular}{|c|c|c|c|c|c|c|}
\hline \multirow[t]{2}{*}{ As exposures $(20 \mu \mathrm{g} / \mathrm{L})$} & \multirow[t]{2}{*}{ As accumulation $(\mu \mathrm{g} / \mathrm{g} \mathrm{dw})$} & \multirow[t]{2}{*}{ THC $\left(\times 10^{6}\right.$ hemocytes/mL hemolymph $)$} & \multirow[t]{2}{*}{$\operatorname{ROS}\left(\mathrm{AU} \times 10^{4}\right)$} & \multicolumn{3}{|c|}{ Antioxidant enzyme activity (U/mg protein) } \\
\hline & & & & SOD & GST & GPx \\
\hline Control & $1.93 \pm 0.12$ & $3.42 \pm 0.67$ & $3.99 \pm 1.29$ & $3.87 \pm 0.87$ & $54.73 \pm 4.08$ & $5.18 \pm 1.55$ \\
\hline As (III) & $2.21 \pm 0.17^{*}$ & $3.82 \pm 0.99$ & $5.46 \pm 0.78^{*}$ & $3.89 \pm 0.38$ & $50.32 \pm 8.11$ & $6.05 \pm 2.36$ \\
\hline As (V) & $2.15 \pm 0.11^{*}$ & $3.68 \pm 0.35$ & $6.83 \pm 1.77^{*}$ & $3.44 \pm 0.52$ & $43.72 \pm 13.89^{\#}$ & $2.88 \pm 1.45^{\#}$ \\
\hline
\end{tabular}

Data were expressed as mean \pm SD. Significant differences among groups were tested for by one-way analysis of variance with Tukey's test.

${ }^{*} p<0.05$.

$\# 0.05<p<0.1$.

plasma-mass spectrometry (ICP-MS) (Agilent 7500i, Agilent Technologies Co. Ltd., USA). GBW08571 Marine muscle tissue (State Bureau of Technical Supervision, People's Republic of China) was used as certified reference material for the analysis of total arsenic to ensure internal quality assurance/quality control $(\mathrm{QA} / \mathrm{QC})$ practices [25].

\subsection{Statistical analysis}

The biochemical indices, including THC, ROS, enzyme activities and total arsenic concentrations in clam digestive gland tissues, were expressed as means \pm standard deviation and tested for normal distribution (Ryan-Joiner's test) and homogeneity of variances (Bartlett's test). One way analysis of variance (ANOVA) with Tukey's test was conducted on these biochemical indices from control and As-exposed groups, respectively. A $p$ value less than 0.05 was considered statistically significant. The Minitab software (Version 15, Minitab Inc., USA) was used for the statistical analysis.

\section{Results and discussion}

Clam $R$. philippinarum can usually accumulate significant amount of metals or metalloids in its tissues, such as gills and digestive glands [26]. The significant accumulations of arsenic were detected in clam digestive gland tissues with both As (III) and As (V) exposures for $48 \mathrm{~h}$ (Table 1 ). As shown in Table 1, the total arsenic concentrations between As (III) and As (V) treatments were not significantly different $(p>0.05)$. In our previous study, As (V) treatment induced significant expression of arsenite-resistance protein in clam $R$. philippinarum, which meant that As (V) could be transformed into As (III) in clams [27]. Therefore, As (III) and As (V) exposures might induce both similar and differential biological effects in clams.

Marine mollusks have an open circulatory system with haemocytes distributed in both vascular system and tissues. It is suggested that increased THC values may be caused by either proliferation or movement of cells from tissues into haemolymph [28]. It has been reported that Vibrio tapetis can induce high THC in haemolymph in $R$. philippinarum to enhance the resistance to bacterial infection [29]. In this study, however, the average values of THC in haemolymph were slightly elevated in both As (III)- and As (V)-exposed clam samples without statistical significances (Table 1), which implied that both As (III) and As (V) treatments did not induce significant effects at cellular level in clam R. philippinarum.

Significant increases $(p<0.05)$ of ROS production were observed in both As (III)- and As (V)-treated clam groups, which suggested that both As (III) and As (V) exposures induced oxidative stress in clam digestive gland tissues. Antioxidant enzyme system is the basic defense system to resist the oxidative stress by scavenging of ROS induced by environmental stressors [30]. Superoxide dismutases (SODs, EC 1.15.1.1) are metalloenzymes that play a vital role in resisting excessive ROS-induced oxidative stress by catalyzing the dismutation of superoxide into molecular oxygen and hydrogen peroxide [30]. In both arsenic treatments, however, SOD activities were not significantly altered $(p>0.05)$, which probably meant that both chemical forms of arsenic exposures did not induce excessive superoxide anions in clam digestive gland. Both glutathione S-transferase (GST, EC 2.5.1.18) and glutathione

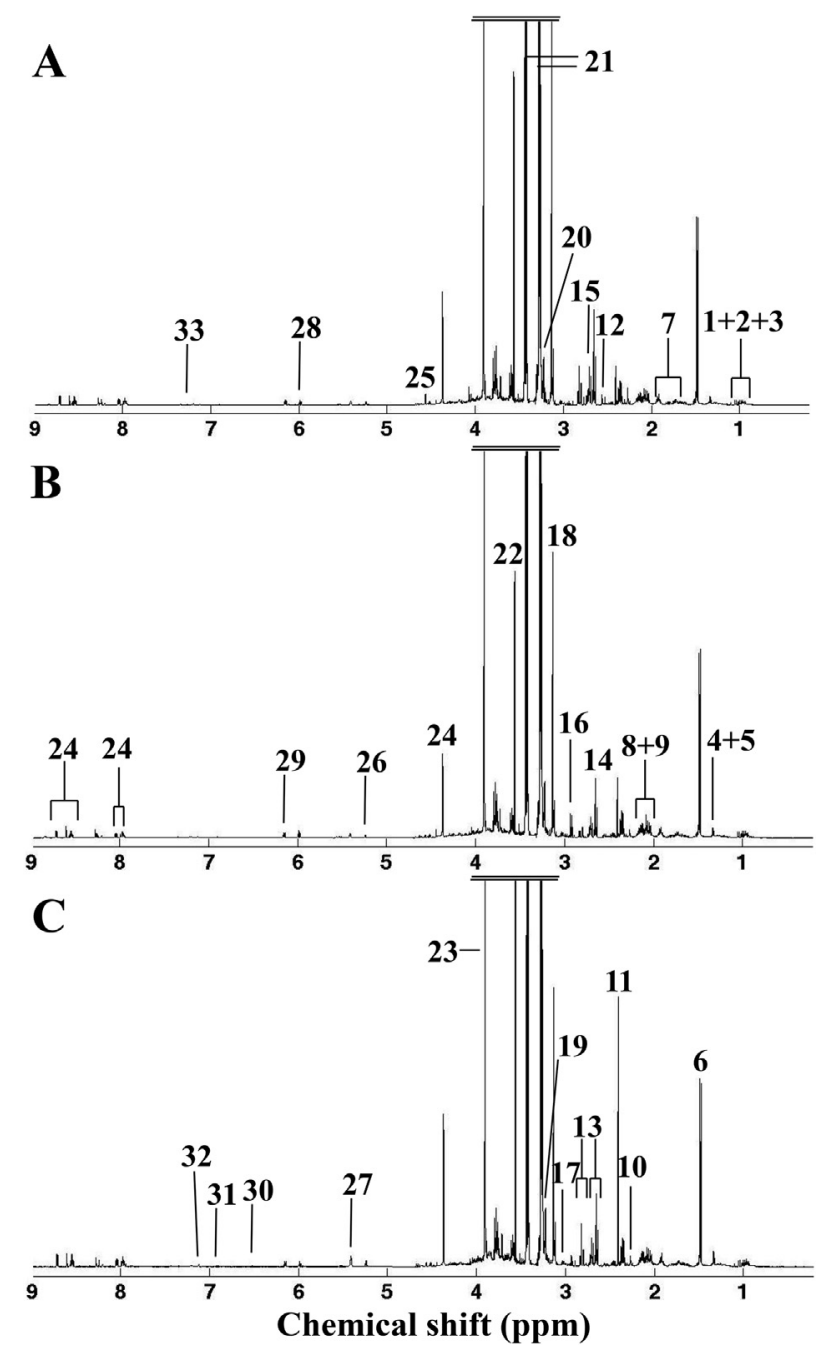

Fig. 1. Representative 1-dimensional $500 \mathrm{MHz}{ }^{1} \mathrm{H}$ NMR spectra of tissue extracts from digestive glands of $R$. philippinarum from (A) control, (B) arsenite $(20 \mu \mathrm{g} / \mathrm{L})$ and (C) arsenate $(20 \mu \mathrm{g} / \mathrm{L})$ treatments. Keys: (1) isoleucine, (2) leucine, (3) valine, (4) threonine, (5) lactate, (6) alanine, (7) arginine, (8) glutamate, (9) glutamine, (10) acetoacetate, (11) succinate, (12) $\beta$-alanine, (13) aspartate, (14) dimethylamine, (15) hypotaurine, (16) dimethylglycine, (17) lysine, (18) malonate (19) choline, (20) phosphocholine, (21) taurine, (22) glycine, (23) betaine, (24) homarine, (25) $\beta$-glucose, (26) $\alpha$-glucose, (27) glycogen, (28) unknown (5.98 ppm), (29) ATP, (30) fumarate, (31) tyrosine, (32) histidine and (33) phenylalanine. 


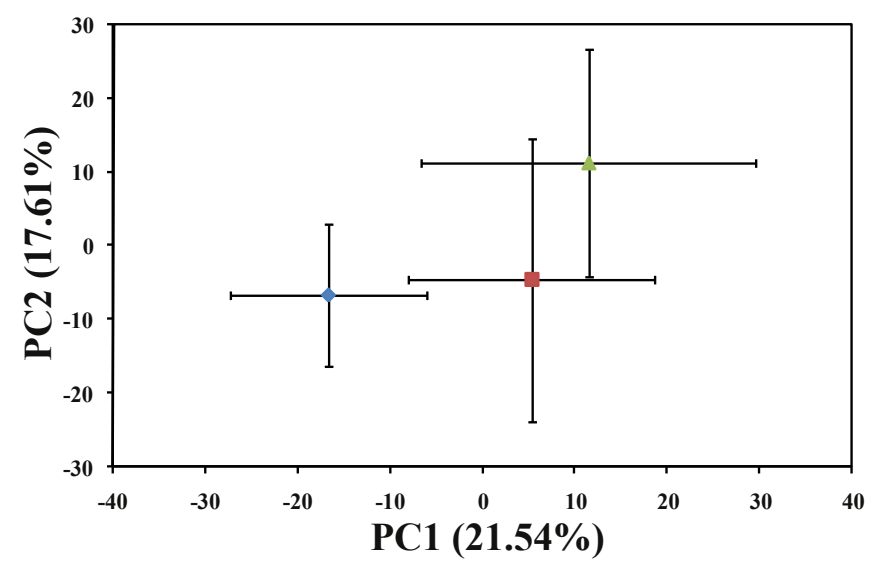

Fig. 2. Mean principal component analysis (PCA) scores plot of PC1 versus $\mathrm{PC} 2$ for ${ }^{1} \mathrm{H}$ NMR spectra of tissue extracts from digestive glands of $R$. philippinarum from control $(\diamond)$, arsenite $(20 \mu \mathrm{g} / \mathrm{L}, \square)$ and arsenate $(20 \mu \mathrm{g} / \mathrm{L}, \Delta)$ treatment. The classes were presented as mean \pm standard deviation (as associated standard error) of PC scores for each group of clam samples.

peroxidase (GPx, EC 1.11.1.9) are related to GSH cycles promoting the conversion of GSH to resist the oxidative stress caused by environmental stressors. However, both GST and GPx activities were depleted in As (V)-treated clam samples with $p$ values approaching or less than 0.05 , respectively (Table 1 ), which might be accounted for the down-regulated synthesis of GST and GPx caused by As (V) in clam samples. In our previous studies, the typical heavy metal contaminant, $\mathrm{Cd}$, inhibited the mRNA expressions of GST and GPx in clams after exposure for $48 \mathrm{~h}$ $[18,19]$. Similarly, the depletion of GST and GPx activities might imply that As (V) inhibited the mRNA expressions and subsequent protein expressions of GST and GPx in clams.

Metabolomics is a newly-established -omic approach that is widely used to characterize the biological effects of environmental stressors in organisms $[22,23,31,32]$. In this study, a total of 32 metabolites, including amino acids (valine, leucine, isoleucine, threonine, alanine, arginine, glutamate, etc.), intermediates in the Krebs cycle (succinate and fumarate), organic osmolytes (hypotaurine, dimethylglycine, betaine, taurine and homarine), energy storage compounds (glucose, ATP and glycogen), in clam digestive glands were identified and labeled in Fig. 1. PCA was performed on the NMR spectral data from control, As (III)- and As (V)-treated clam samples. Obviously, PCA resulted in significant $(p<0.01)$ separations between control and arsenic-treated groups along PC1 axis (Fig. 2). It clearly demonstrated the significant metabolic differences between control and both arsenic treatments.

O-PLS-DA was performed on the NMR spectral data from control and each arsenic-treated clam samples (Fig. 3), resulting in clear separations between control and As treatments with $\mathrm{Q}^{2}$ values greater than 0.4 and $\mathrm{R}^{2} \mathrm{Y}$ values larger than 0.9 (Fig. $3 \mathrm{~A}$ and $\mathrm{C}$ ), which suggested that both As treatments induced significant metabolic responses in clam digestive glands. From the loading plot (Fig. 3B), the As (III) exposure induced significant $(p<0.05)$ increases in branched chain amino acids (BCAAs), alanine, glutamate, succinate, hypotaurine, asparagine, lysine, choline, ATP, tyrosine and phenylalanine and decreases in aspartate and betaine. In As (V)-treated clam samples, BCAAs, alanine, glutamate, succinate, hypotaurine, lysine, choline, tyrosine, aspartate and betaine were
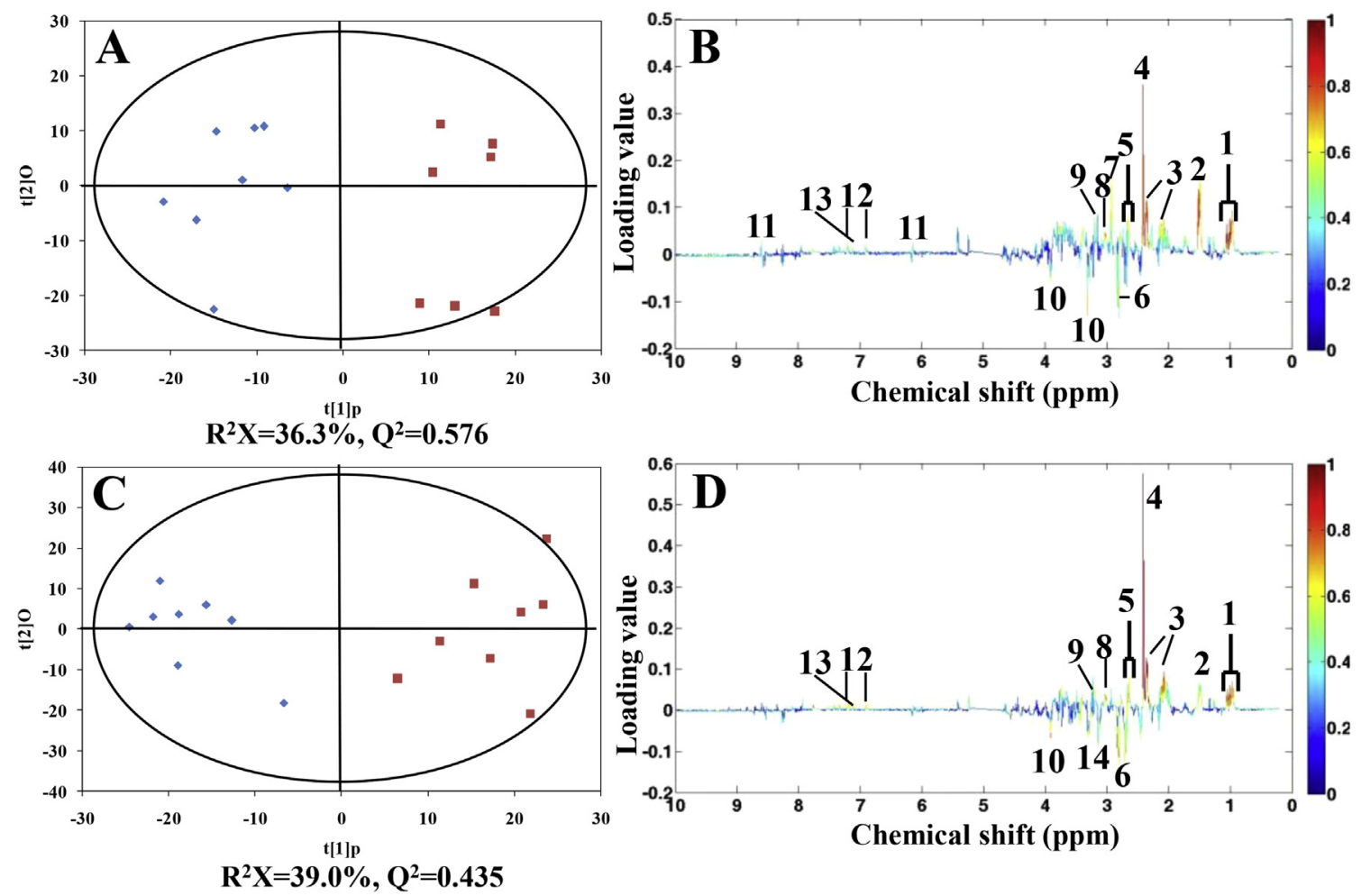

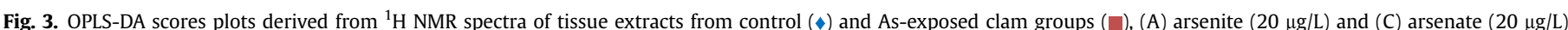

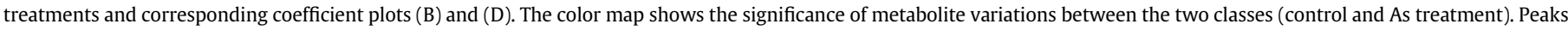

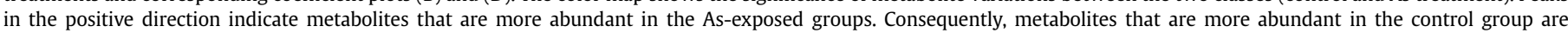

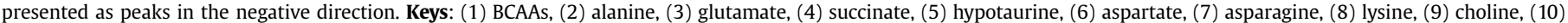

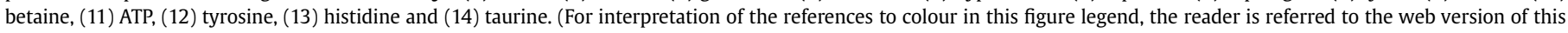
article.) 
similarly altered. However, some differentially altered metabolic responses were observed in the As (V)-treated clam samples. In particular, histidine was elevated, whereas taurine was depleted (Fig. 3D).

In marine mollusks, amino acids are involved in multiple metabolic pathways. As it is known, free amino acids are organic osmolytes regulating the intracellular osmolarity with the saline environment [33]. In addition, amino acids can be oxidized for energy supply through Krebs cycle. Since the organic osmolyte, hypotaurine, was obviously elevated in As (III)- and As (V)-treated clam samples, the elevated amino acids might indicate the osmotic stress induced by both As (III) and As (V). However, the intermediate in Krebs cycle, succinate was significantly increased, together with ATP, which suggested that the elevated amino acids were also related to the enhanced energy demand caused by both arsenic exposures. Specifically, alanine constitutes the major portion of end-product of glucose breakdown anaerobically, together with the metabolite of succinate in invertebrate [34]. In addition, there could be a substantial conversion of aspartate to succinate under anoxic conditions in mollusk hence with decreased aspartate and increased succinate [35]. As an important intermediate in amino acids metabolism, aspartate is involved in multiple biological processes including biosynthesis of amino acids, urea cycle and gluconeogenesis. Interestingly, decreased aspartate and increased succinate were found in both arsenic-treated clam groups. Therefore, the high levels of alanine and succinate and low levels of aspartate demonstrated the enhanced anaerobiosis induced by both As (III) and As (V) exposures in clams. The branched chain amino acids, including valine, leucine and isoleucine, have availability on the immune system to function by incorporating BCAAs into proteins [36]. Upon pathogenic infection, there is a remarkable increase in demand for BCAAs for substrates by the immune system [36]. These BCAAs then provide energy and are used as the precursors for the biosynthesis of new protective molecules [36]. Therefore, the increased BCAAs might suggest the immune stress in clam immune organ, digestive gland, induced by both arsenic exposures.

Choline can be oxidized to betaine that serves as an organic osmolyte playing an important role in osmotic regulation in marine mollusks [33]. The elevated choline and depleted betaine implied the reduced conversion from choline to betaine induced by both arsenic exposures in clams. Additionally, the depleted betaine might be used to compensate the increase of amino acids and hypotaurine involved in osmotic regulation in both arsenic-treated clam groups. The amino acid, histidine, was increased and the organic osmolyte, taurine was uniquely decreased in As (V)-treated clam group, which suggested that As (V) induced more severe disturbance in osmotic regulation in clam than As (III).

In summary, multiple biochemical indices were measured to characterize the biological effects induced by two inorganic chemical forms of arsenic (arsenite and arsenate) in the digestive glands of clam Ruditapes philippinarum. The ROS and antioxidant enzymes exhibited that both As (III) and As (V) induced oxidative stresses in clam digestive glands. Meanwhile, metabolic responses showed that both As (III) and As (V) exposures caused immune stress evidenced by the elevated branched chain amino acids (valine, leucine and isoleucine). Both arsenic exposures induced osmotic stress in clams. However, the differential metabolic biomarkers, histidine and taurine, indicated the differential responsive mechanisms in osmotic regulation in clam digestive glands. In addition, both arsenic treatments enhanced the anaerobiosis metabolism in clam digestive glands. Overall, this work illustrated that arsenite and arsenate induced similar biological effects in clams, which might be accounted for the biological transformation of arsenate to arsenite in clams.

\section{Acknowledgments}

This work was supported by National Key Basic Research Program of China (2015CB453303) and Natural Science Foundation of Shandong Province (No. JQ201310). We thank Prof. Mark Viant (School of Bioscience, The University of Birmingham) for the use of ProMetab software.

\section{References}

[1] J. Ventura-Lima, J.Z. Sandrini, M. Ferreira-Cravo, F.R. Piedras, T.B. Moraes, D. Fattorini, A. Notti, F. Regoli, L.A. Geracitano, L.F. Marins, J.M. Monserrat, Toxicological responses in Laeonereis acuta (Annelida, Polychaeta) after arsenic exposure, Environ. Int. 33 (2007) 559-564.

[2] Bulletins of Chinese Marine Environment Quality, State Oceanic Administration, P. R. China, 2007-2010.

[3] C.F. Harrington, A.A. Ojo, V.W.M. Lai, K.J. Reimer, W.R. Cullen, The identification of some water-soluble arsenic species in the marine brown algae Fucus distichus, Appl. Organometal Chem. 11 (1997) 931-940.

[4] J.M. Neff, Ecotoxicology of arsenic in the marine environment, Environ. Toxicol. Chem. 16 (1997) 917-927.

[5] D.J.H. Phillips, M.H. Depledge, Distribution of inorganic and total arsenic in tissues of the marine gastropod Hemifusus ternatanus, Mar. Ecol. Prog. Ser. 34 (1986) 261-266.

[6] T.D. Williams, N. Turan, A.M. Diab, H. Wu, C. Mackenzie, K.L. Bartie, O. Hrydziuszko, B.P. Lyons, G.D. Stentiford, J.M. Herbert, J.K. Abraham, I. Katsiadaki, M.J. Leaver, J.B. Taggart, S.G. George, M.R. Viant, K.J. Chipman, F. Falciani, Towards a system level understanding of non-model organisms sampled from the environment: a network biology approach, PLoS Comput. Biol. 7 (2011) 1-20.

[7] X. Liu, C. Ji, J. Zhao, Q. Wang, F. Li, H. Wu, Metabolic profiling of the tissuespecific responses in mussel Mytilus galloprovincialis towards Vibrio harveyi challenge, Fish Shellfish Immunol. 39 (2014) 372-377.

[8] C. Ji, H. Wu, L. Wei, J. Zhao, iTRAQ-based quantitative proteomic analyses on the gender-specific responses in mussel Mytilus galloprovincialis to tetrabromobisphenol A, Aquat. Toxicol. 157 (2014) 30-40.

[9] H. Wu, C. Ji, L. Wei, J. Zhao, Evaluation of protein extraction protocols for 2DE in marine ecotoxicoproteomics, Proteomics 13 (2013) 3205-3210.

[10] H. Wu, X. Zhang, X. Li, Z. Li, Y. Wu, F. Pei, Comparison of metabolic profiles from serum for the hepatotoxin-treated rats by NMR spectroscopic-based metabonomic analysis, Anal. Biochem. 340 (2005) 99-105.

[11] X. Zhang, H. Wu, P. Liao, X. Li, J. Ni, F. Pei, NMR-based metabonomic study on the subacute toxicity of aristolochic acid in rats, Food Chem. Toxicol. 44 (2006) 1006-1014.

[12] T.D. Williams, H. Wu, E. Santos, J. Ball, I. Katsiadaki, M.M. Brown, P. Baker; F. Ortega, F. Falciani, J.A. Craft, C.R. Tyler, J.K. Chipman, M.R. Viant, Hepatic transcriptomic and metabolomic responses in the stickleback (Gasterosteus aculeatus) exposed to environmentally relevant concentrations of dibenzanthracene, Environ. Sci. Technol. 43 (2009) 6341-6348.

[13] H. Wu, W.-X. Wang, Tissue-specific toxicological effects of cadmium in green mussel (Perna viridis): nuclear magnetic resonance-based metabolomics study, Environ. Toxicol. Chem. 30 (2011) 806-812.

[14] E. Santos, J.S. Ball, T.D. Williams, H. Wu, F. Ortega, R. Van Aerle, I. Katsiadaki, F. Falciani, M.R. Viant, J.K. Chipman, C.R. Tyler, Identifying health impacts of exposure to copper using transcriptomics and metabolomics in a fish model, Environ. Sci. Technol. 44 (2010) 820-826.

[15] L. Zhang, X. Liu, L. You, D. Zhou, Q. Wang, F. Li, M. Cong, L. Li, J. Zhao, D. Liu, J. Yu, H. Wu, Benzo(a)pyrene-induced metabolic responses in Manila clam Ruditapes philippinarum by proton nuclear magnetic resonance $\left({ }^{1} \mathrm{H}\right.$ NMR) based metabolomics, Environ. Toxicol. Pharmacol. 32 (2011) 218-225.

[16] L. Zhang, X. Liu, L. You, D. Zhou, H. Wu, L. Li, J. Zhao, J. Feng, J. Yu, Metabolic responses in gills of Manila clam Ruditapes philippinarum exposed to copper using NMR-based metabolomics, Mar. Environ. Res. 72 (2011) 33-39.

[17] C. Li, H. Sun, A. Chen, X. Ning, H. Wu, S. Qin, Q. Xue, J. Zhao, Identification and characterization of an intracellular $\mathrm{Cu}, \mathrm{Zn}$-superoxide dismutase (icCu/ $\mathrm{Zn}-\mathrm{SOD}$ ) gene from clam Venerupis philippinarum, Fish Shellfish Immunol. 28 (2010) 499-503.

[18] L. Zhang, X. Liu, L. Chen, L. You, D. Pei, M. Cong, J. Zhao, C. Li, D. Liu, J. Yu, $\mathrm{H}$. Wu, Transcriptional regulation of selenium-dependent glutathione peroxidase from Venerupis philippinarum in response to pathogen and contaminants challenge, Fish Shellfish Immunol. 31 (2011) 831-837.

[19] L. Zhang, L. Qiu, H. Wu, X. Liu, L. You, D. Pei, L. Chen, Q. Wang, J. Zhao, Expression profiles of seven glutathione $S$-transferase (GST) genes from Venerupis philippinarum exposed to heavy metals and benzo[a]pyrene, Comp. Biochem. Physiol. Part C 155 (2012) 517-527.

[20] W. Meng, Z. Liu, W. Fan, Study on pollutant characters of main estuary of Bohai Bay (in Chinese), Res. Environ. Sci. 17 (2004) 66-69.

[21] M. Delaporte, P. Soudant, J. Moal, C. Lambert, C. Quéré, P. Miner, G. Choquet, C. Paillard, J. Samain, Effect of a mono-specific algal diet on immune functions in two bivalve species - Crassostrea gigas and Ruditapes philippinarum, J. Exp. Biol. 206 (2003) 3053-3064.

[22] J. Feng, J. Li, H. Wu, Z. Chen, Metabolic responses of HeLa cells to silica 
nanoparticles by NMR-based metabolomic analyses, Metabolomics 9 (2013) $874-886$.

[23] X. Liu, L. Zhang, L. You, M. Cong, J. Zhao, H. Wu, C. Li, D. Liu, J. Yu, Toxicological responses to acute mercury exposure for three species of Manila clam Ruditapes philippinarum by NMR-based metabolomics, Environ. Toxicol. Pharmacol. 31 (2011) 323-332.

[24] M. Bradford, A rapid and sensitive method for the quantification of microgram quantities of protein utilizing the principle of protein-dye binding, Anal. Biochem. 72 (1976) 248-254.

[25] L. Li, X. Liu, L. You, L. Zhang, J. Zhao, H. Wu, Uptake pathways and subcellular fractionation of $\mathrm{Cd}$ in the polychaete Nereis diversicolor, Ecotoxicology 21 (2012) 104-110.

[26] M.J. Bebianno, M.A. Serafim, Comparison of metallothionein induction in response to cadmium in the gills of the bivalve mollusks Mytilus galloprovincialis and Ruditapes decussates, Sci. Total Environ. 214 (1998) 123-131.

[27] H. Wu, X. Liu, X. Zhang, C. Ji, J. Zhao, J. Yu, Proteomic and metabolomic responses of clam Ruditapes philippinarum to arsenic exposure under different salinities, Aquat. Toxicol. 136-137 (2013) 91-100.

[28] R.K. Pipe, J.A. Coles, Environmental contaminants influencing immune function in marine bivalve molluscs, Fish Shellfish Immunol. 5 (1995) 581-595.

[29] H.I. Reid, P. Soudant, C. Lambert, C. Paillard, T.H. Birkbeck, Salinity effects on immune parameters of Ruditapes philippinarum challenged with Vibrio tapetis,
Dis. Aquat. Org. 56 (2003) 249-258

[30] C. Yang, S, Liu, S. Zhou, H. Wu, J. Yu, C. Xia, Allelochemical ethyl 2-methyl acetoacetate (EMA) induces oxidative damage and antioxidant responses in Phaeodactylum tricornutum, Pestic. Biochem. Physiol. 100 (2011) 93-103.

[31] Z. Li, H. Wu, X. Zhang, X. Li, P. Liao, W. Li, F. Pei, Investigation on the acute biochemical effects of light rare earths (lanthanum and cerium) by NMRbased metabonomic approaches, Chem. J. Chin. Univ. 27 (2006) 438.

[32] X. Liu, C. Yang, L. Zhang, L. Li, S. Liu, J. Yu, L. You, D. Zhou, C. Xia, J. Zhao, H. Wu, Metabolic profiling of cadmium-induced effects in one pioneer intertida halophyte Suaeda salsa by NMR-based metabolomics, Ecotoxicology 20 (2011) 1422-1432.

[33] M.R. Viant, E.S. Rosenblum, R.S. Tjeerdema, NMR-based metabolomics: a powerful approach for characterizing the effects of environmental stressors on organism health, Environ. Sci. Technol. 37 (2003) 4982-4989.

[34] T.M. Stokes, A. Awapara, Alanine and succinate as end-products of glucose degradation in the clam Rangia cuneata, Comp. Biochem. Physiol. 25 (1968) 883-892.

[35] R.A. Graham, W.R. Ellington, Anaerobic aspartate metabolism and the formation of alanine in molluscan cardiac muscle: a ${ }^{13} \mathrm{C}$ NMR study, J. Exp. Zool 236 (1985) 365-370.

[36] P.C. Calder, Branched chain amino acids and immunity, J. Nutr. 136 (2006) 288S-293S. 